\title{
Recovery and compensatory strategies in head injured memory impaired people several years after insult
}

\author{
Barbara Wilson
}

\begin{abstract}
A follow up study of 29 patients with traumatic head injury who were referred for memory therapy five to 10 years earlier is described. Of the original sample, 28 were traced, one had died, and one refused to take part, thus leaving 26 subjects who were seen and reassessed. Most (21) were living in their own homes with relatives, friends or alone; the others were in long term residential care or residential college or in warden controlled accommodation. Eleven subjects were in paid employment, although only one was in a position comparable to pre-injury status. On a standardised memory test some $58 \%$ of subjects showed no change since their last assessment several years earlier; $31 \%$ improved; and $11 \%$ deteriorated. The most encouraging finding was that subjects were using more memory aids and strategies now than before or at the end of their rehabilitation programme.
\end{abstract}

Few studies have looked at the long term fate of severely head injured people who survive with significant memory deficits. Schacter and Crovitz ${ }^{1}$ report on the incidence of memory impairment after head injury; and others ${ }^{2-4}$ found that families frequently report memory problems in their head injured relatives when questioned several years after original insult. Previous studies have not revealed whether memory problems are resolved over time; nor do they provide us with any insight into ways memory impaired people might or might not cope in their daily lives over long periods of time. We know that one densely amnesic patient, did not show recovery or improvement over a 30 year period. ${ }^{5}{ }^{6}$ However, the patient had bilateral hippocampal lesions when surgery was carried out in an attempt to reduce his very severe epilepsy. No similar study has been identified which follows a severely head injured and amnesic patient over a period of several years. Nor does there seem to have been any long-term study of a group of memory impaired people.

This paper describes a follow up study of 29 patients with traumatic head injury (THI) who were referred for memory therapy five to 10 years earlier. These subjects were part of a larger group of 54 patients. $^{7}$ The larger group was comprised of patients with stroke, Korsakoff's syndrome, anoxia and epilepsy as well as THI.

\section{Subjects}

The 29 THI patients were aged between 13 and 61 years at the time of insult, with a mean (SD) age of 25 (10) years, a modal age of 19 years, and a median age of 21 years. There were 11 females and 18 males. The mean (SD) age of the females was higher $(27.18(12.93)$ years) than that for males $(23.94(7 \cdot 59)$ years). Road traffic accidents were the most frequent cause of head injury for both males and females, with 24 subjects being involved. Two men and one woman sustained severe head injury resulting from falls, one young woman was involved in a horseriding accident, and the remaining man was the victim of an assault.

The mean (SD) length of coma (ascertained from records in hospital notes) was 5.03 (5.56) weeks. The modal length was four weeks, the median length was three weeks. The mean (SD) was $4 \cdot 25(4 \cdot 86)$ weeks, and the range was one hour to 24 weeks.

All subjects had been referred for memory therapy which took place between five to 10 years before follow up investigation, that is, six to 11 years post injury. Inclusion criteria for each subject accepted for that memory therapy were as follows: 1) The subject showed no evidence of dysphasia as assessed by speech therapists; 2) The subject had received a psychological assessment; 3) The subjects' scores were in the impaired range on at least two memory tests including the Rivermead Behavioural Memory Test (Wilson, Cockburn and Baddeley, 1985).

\section{Memory therapy}

The therapy offered to each subject varied according to the needs of the individual as agreed by a team of therapists. However, a typical programme lasting six weeks was designed in the following manner.

1) Identification of specific problem areas through:

a) Assessment (neuropsychological and behavioural)

b) Observation in rehabilitation departments

c) Discussions with the patient, relatives and staff

2) Treatment of problems by:-

a) Selection of goals

b) Baselines

c) Implementation of treatment plan

d) Monitoring

e) Evaluation (through monitoring and single case experimental designs)

f) Generalisation procedures

3) Additional therapy, if required, including

a) Relaxation 
b) Counselling

c) Help with perceptual and reading problems

d) Modification of disruptive behaviour

In addition to individual memory therapy,

22 of the 29 subjects participated in at least one memory programme organised on a group basis. Memory groups were organised in the following manner:

1) Between four to six people in each group

2) Group members met for 45 minutes each weekday

3) Sessions ran for three weeks

Strategies covered in group sessions included:

1) Orientation exercises

2) Discussions of problem solving techniques

3) Introduction to and practice in the use of external aids

4) Introduction to and practice in the use of internal strategies and mnemonics

5) Memory games and exercises

Further descriptions of individual and group programmes can be found in Wilson ${ }^{8}$ and Wilson and Moffat. ${ }^{9}$

Follow up study

One of the subjects had committed suicide at the age of 30 years, that is, five years after his head injury. Two others could not be traced, one man who sustained his head injury at the age of 28 years, and the other at the age of 42 years. One young woman, aged 17 years when she was injured, refused to take part in the study although she gave some information by letter. The remaining 25 people were seen and reassessed on the following measures.

1) A questionnaire asking about current problems, employment, social contacts and accommodation

2) A questionnaire about the use of memory aids and strategies.

Subjects were asked whether they used a particular strategy now and whether they used it before the accident.

Information was checked with a relative or carer. Ratings given several years earlier, that is, before and after the memory therapy, were also available.

3) Two standardised memory tests (the $\mathrm{RBMT}^{10}$ and the Wechsler Memory Scale Revised). ${ }^{11}$

4) Other non-standardised memory tests of remote and recent memory.

\section{Results}

The results from (1) are not reported here as this information has been reported in other studies. $^{23}$

Use of memory aids and strategies. Most subjects reported using more aids when reassessed than they were both before the THI and during the time they were receiving memory therapy. The mean number of aids used per subject can be seen in table 1 .

The number of individuals using each type of strategy can be seen in table 2. A Wilcoxon matched pairs signed ranks test shows the increase is significant $(T=0, p<0.01)$.

The most frequently reported aids or strate-
Table 1 The mean number of memory aids and strategies used per person before sustaining a severe head injury, at the end of therapy, and at follow up

\begin{tabular}{llll}
\hline & $\begin{array}{l}\text { Before } \\
(\mathrm{N}=25)\end{array}$ & $\begin{array}{l}\text { After Memory Therapy } \\
(\mathrm{N}=18)\end{array}$ & $\begin{array}{l}\text { Now } \\
(\mathrm{N}=25)\end{array}$ \\
\hline $\mathrm{X}$ & 3.96 & 4.6 & 7.56 \\
$\mathrm{SD}$ & 2.10 & 2.14 & 2.99 \\
\hline
\end{tabular}

Table 2 Frequency of use of memory aids and strategies $(N=25)$ before injury and at follow up

\begin{tabular}{lcl}
\hline Aid or Strategy & $\begin{array}{l}\text { No. of subjects } \\
\text { using before } \\
\text { injury }\end{array}$ & $\begin{array}{l}\text { No. of subjects } \\
\text { using at } \\
\text { follow up }\end{array}$ \\
\hline asking others to remind you & 6 & 16 \\
mental retracing of events & 6 & 16 \\
notebooks, notes & 7 & 15 \\
wall calendar or wall chart & 6 & 15 \\
lists & 10 & 14 \\
alarm clock & 13 & 14 \\
watch with date & 11 & 13 \\
leaving objects in an unusual & 6 & 12 \\
place & 10 & 10 \\
appointment diary & 2 & 10 \\
visual imagery & 2 & 9 \\
alphabetic searching & 0 & 6 \\
dictaphone or tape recorder & 5 & 6 \\
watch with timer & 3 & 5 \\
writing on hand & 0 & 0 \\
filofax or personal organiser & 0 & 0 \\
PQRST & & $12^{\star \star}$ \\
other & 0 &
\end{tabular}

^PQRST is an acronym for Preview, Question, Read, State, Test

$\star \star$ that is, 12 individuals reported using other strategies. The number of strategies described equalled 25 .

Table 3 "Other" strategies used by the head injured subjects (none of which were used before the head injury)

\begin{tabular}{ll}
\hline Strategy & $\begin{array}{l}\text { Number of } \\
\text { individuals }\end{array}$ \\
\hline Making associations to things already known & 5 \\
Extra effort or rehearsal & 5 \\
First letter mnemonics & 3 \\
Always placing object in same area of room & 2 \\
Checking special places regularly for notes & 2 \\
Relying on another person to act as memory & 2 \\
Rhymes & 1 \\
Leaving pin on phone book to remember to & 1 \\
telephone & 1 \\
Carrying daily timetable on card & 1 \\
Making a pleasantness rating to help remember & 1 \\
faces & \\
Chunking/grouping & 1 \\
table as reminders to replace & 1 \\
\hline
\end{tabular}

gies in the "other" category can be seen in table 3:

Standardised memory tests. On the RBMT screening score, with a maximum of 12 , the group as a whole had improved (see table 4).

A Friedman non-parametric analysis showed these changes were significantly different $(p<0.001)$ and the Wilcoxon matched pairs test indicated that the change in scores from before therapy to immediately after therapy is significant at the $1 \%$ level whereas the change between the end of therapy and the long-term follow up is significant at the $5 \%$ level.

The changes in mean score do not, however, give an accurate picture. For example, one young man sustained a second severe head injury during the follow-up period and this led to a fall in his scores. Using the more stringent 
Table 4 RBMT screen scores before and after therapy and at follow up

\begin{tabular}{lll}
\hline $\begin{array}{l}\text { Mean }(S D) \\
\text { screening } \\
\text { score before therapy }\end{array}$ & $\begin{array}{l}\text { Mean }(S D) \\
\text { screening } \\
\text { score after therapy }\end{array}$ & $\begin{array}{l}\text { Mean }(S D) \\
\text { screening } \\
\text { score now }\end{array}$ \\
\hline $2.47(2 \cdot 74)$ & $4 \cdot 28(3.02)$ & $5 \cdot 16(3 \cdot 20)$ \\
\hline
\end{tabular}

Table 5 Change in RBMT scores and length of coma

\begin{tabular}{llll}
\hline & $\begin{array}{l}\text { Improved } \\
\text { scores } \\
(N=8)\end{array}$ & $\begin{array}{l}\text { Unchanged } \\
\text { scores } \\
(N=14)\end{array}$ & $\begin{array}{l}\text { Worse } \\
\text { scores } \\
(N=3)\end{array}$ \\
\hline Mean length of & & & \\
coma (weeks) & 1.97 & $6 \cdot 15$ & 8.66 \\
SD (weeks) & 1.42 & $6 \cdot 25$ & $4 \cdot 7$ \\
Range (weeks) & $0.1-4$ & $1.5-24$ & $2-12$ \\
\hline
\end{tabular}

measures of improvement obtained when change equals three or more screening score points, we see that 14 people did not change between the end of therapy and follow-up, eight showed an improvement, and three showed a deterioration. The last group contained the man who had sustained a second head injury.

Those who improved had a shorter length of coma than those who did not improve as can be seen from table 5 .

Another way of scoring the RBMT is to use the more sensitive standardised profile score which ranges from 0-24. Unfortunately, this method was not available during the time most of the present subjects were receiving their memory therapy. However, if we look at those who obtained an RBMT standardised profile score of 11 or more compared with those scoring 10 or less and look at independence or dependence then the RBMT is a good predictor of ability to live independently $\left(\chi^{2}=\right.$ 18.08 , $\mathrm{df}=1, \mathrm{p}<0.001)$. Independence is operationally defined as fulfilling one of the following: 1) living alone, 2) in paid employment, or 3) in full-time education.

When the Wechsler Memory Scale-Revised was applied to the same subjects for the purpose of distinguishing between "independent" and "dependent" living, it was unable to discriminate so well. On the delayed memory index, for example, 11 subjects scored below 50 (the lowest index score obtainable). Of these 11 , seven were independent, that is, living alone or in paid employment or full-time education.

On the other non-standardised tests of memory, the independent subjects tended to score less on a true-false test of current news events, and tended to have longer periods of retrograde amnesia. They also performed poorly on a brief test of autobiographical memory.

\section{Discussion}

What do these results tell us about recovery amongst memory impaired head injured people? To answer this question we must first define what we mean by the term "recovery". Almli and Finger ${ }^{12}$ offer eight different definitions, ranging from "resumption of normal life even though there may be minor neurological and psychological changes"13 through to "achievement of a goal"14 and "the post lesion reinstatement of the specific behaviours that were disrupted by the brain injury". ${ }^{15}$

Almli and Finger argue that recovery is a theoretical construct that implies a complete regaining of the identical functions that were lost or impaired after brain injury. ${ }^{12}$ If we apply this theoretical construct to the everyday, practical reality faced by subjects in this study, we would have to say that none of them recovered their memory functioning. Only one subject obtained entirely normal scores on the two standardised memory tests, and she showed evidence of a retrograde amnesia, suggesting that her memory functioning was almost certainly not identical to her premorbid state.

Less inflexible definitions, such as those offered by Jennett and Bond, and Laurence and Stein ${ }^{13}{ }_{14}$ would allow us to apply the term "recovery" to some of the subjects in this study, but by doing this we could perhaps be accused of bending the language to suit our purposes. In such circumstances, it may be far better to stick to terms like "independence" and "improvement", as these can be applied more specifically to changes that were observed, indeed measured, among the subjects of this study. Eight of them, for example, scored significantly higher on the RBMT: that is, they scored three or more points above their last assessment several years earlier. It can be seen that $56 \%$ showed no change, $32 \%$ showed improvement, and $12 \%$ deteriorated. One of those who deteriorated had sustained a second head injury but the other two declined for no obvious reason. One, a man aged 29 years when reassessed, was in paid employment. He said he was very unhappy with his unskilled and menial job. The other, a young woman aged 26 years when reassessed, attended a day centre and special education classes. One explanation could be that during rehabilitation, when these subjects were receiving several hours of therapy a day for weeks on end, their memory functioning was stretched and working at its maximum efficiency. Once the intensive input stopped, they ceased performing at their peak levels. To accept this explanation it is necessary to argue against Harris and Sunderland, ${ }^{16}$ who claim that memory is not like "a mental muscle" which increases with exercise. The alternative point of view is that memory is indeed like a muscle and will atrophy if not used.

The eight subjects who showed noticeable improvement on the RBMT tended to be those with a shorter coma period. Independence, however, did not appear to be determined by coma. The woman with the longest length of coma (24 weeks) was living alone while three subjects with short lengths of coma (10 days or less) were not independent.

If the present sample is representative, improvement can be expected on formal memory tests in about $32 \%$ of memory impaired head injured people, especially if length of coma among that group is less than three weeks. Additionally, most people can be expec- 
ted to survive outside long-term residential care, and some $64 \%$ can be expected to achieve independence when operational definitions such as "living alone" or "in paid employment" or "in full-time education" are applied.

One reason why more subjects in this study are independent (within the above definitions) than might have been predicted at a time soon after head injury, is that they are using memory aids and strategies to a greater extent now than they were during the rehabilitation period. Thus despite the fact that subjects were introduced to a wide variety of aids during rehabilitation, they only made use of them when forced to do so by the demands of daily living. Their frequency of use compares with the findings of Harris ${ }^{1718}$ who found that both students and housewives made frequent use of a number of memory techniques and, furthermore, they tend to rely more heavily on external aids such as reminders to do things rather than internal strategies which help to store information. The one internal strategy which was frequently used in Harris's study was mental retracing of events-a strategy which does not require a special encoding effort before it can be used. This finding was also true of the present subjects with mental retracing of events coming joint top in the frequency of use.

1 Schacter D, Crovitz $\mathrm{H}$. Memory function after closed head injury: A review of the quantitative research. Cortex
1977;13:105-16.

2 Oddy M. Head injury and social adjustment. In: $\mathrm{N}$ Brooks, ed. Closed head injury: psychological, social and family consequences. Oxford: Oxford University Press, 1984

3 Brooks DN. Cognitive deficits after head injury. In: DN Brooks, ed. F Head injury: psychological, social and family consequences. Oxford: Oxford University Press, consequences.

4 Brooks DN, Campsie L, Symington C, et al. The effects of severe head injury on patient and relative within seven severe head injury on patient and relative within

5 Scoville WB, Milner B. Loss of recent memory after bilateral hippocampal lesions. Neurosurg Psychiatry 1957;20 11-21.

6 Freed DIM, Corkin S, Cohen N. Forgetting in HM: a second look. Neuropsychologia 1987;25:461-72.

7 Wilson BA. Long-term prognosis of patients with severe memory disorders. Neuropsychological Rehab 1991;1(2) 117-134.

8 Wilson BA. Identification and remediation of everyday problems in memory impaired adults. In OA Parsons, $\mathbf{N}$ Butters, PE Nathan, eds. Neuropsychology of alcoholism: implications for diagnosis and treatment. New York: Guilford Press, 1987:322-37.

9 Wilson BA, Moffat N. Running a memory group. In: BA Wilson, N Moffat, eds. Clinical management of memory Wilson, $\mathrm{N}$ Moffat, eds. Clinical management of

10 Wilson BA, Cockburn J, Baddeley AD. The Rivermead Behavioural Memory Test. Bury St Edmunds, Suffolk: Thames Valley Test Company, 1985

11 Wechsler D. The Wechsler Memory Scale - Revised. San Antonio: The Psychological Corporation, 1987.

12 Almli CR, Finger S. Toward a definition of recovery of function. In: S Finger, TE LeVere, CR Almli, DG Stein, eds. Brain injury and recovery. New York: Plenum Press, 1988:1-14.

13 Jennett B, Bond M. Assessment of outcome after severe brain damage. Lancet 1975;1:480-4.

14 Laurence S, Stein DG. Recovery after brain damage and the concept of localisation of function. In: $S$ Finger, eds. Concept of localisation of function. In: $S$ Finger, eds. Recovery from brain dam

15 LeVere TE. Recovery after brain damage: A theory of the behavioural deficit. Physiological Psychology 1988;8: 297-308.

16 Harris JE, Sunderland A. A brief summary of the management of memory disorders in rehabilitation units in Britain. Rehab Med 1981;3:206-9.

17 Harris JE. External memory aids. In: $M$ Gruneberg, $P$ Morris, R Sykes, eds. Practical aspects of memory. London Academic Press, 1978.

18 Harris JE. Memory aids people use: Two interview studies. Memory and Cognition 1980;8:31-8. 